\title{
Surface and volume effects in thermal signatures of buried mines: experiment and modelling
}

\author{
by P. Pręgowski ${ }^{1}$, W. Świderski ${ }^{2}$ and R. T. Walczak ${ }^{3}$
}

${ }_{1}^{1}$ PIRS, Pregowski Infrared Services, 36 Zachodzącego Slońca St, 01-495 Warsaw

${ }^{2}$ Military Institute of Armament Technology (MIAT), 7 Prymasa Wyszyńskiego St., Warsaw

${ }^{3}$ Institute of Agrophysics, Polish Academy of Sciences, 4 Doswiadczalna St, 20-236 Lublin

Abstract

This paper presents models, software and results both experimente and based on simulations. Results of the estimations clarified and quantitatively confirmed the strong influence of moisture gradients and density level of the soil for thermal decompositin on the surface. These multiplicative structural noises caused by surface and subsurface irregularities are the main source of false alarms even in case of mines buried in sand. Better understanding of this phenomenon should help in elaborating more effective prediction and detection procedures of IRT applications.

\section{Introduction}

About 64 nations are presently affected with more than 100 million estimated, still buried. mines. During the last tenths of years numerous sensing methods have been tested but presently the most popular ones seem to be: electromagnetic (EM \& GPR), thermal neutron activation (TN), acoustic, $x$-ray, IR imaging and vapour detection [1]. IR methods proved to be effective in locating fields of antitank mines from airborne platforms yet in the 80's but in last few years IR thermal imaging systems had also been adapted to both vehicle and handheld systems for locating individual mines. The IR cameras provide a key function of most effective - multisensor systems- overall design, offering a horizontal stand-off capability to detect targets prior to encountering them. Passive imaging (IR, VIS) systems were defined as the most simple and most immediately attractive of all detection technologies for the US Marine Corps.[2]

As a matter of fact IR detection of buried mines can be treated as particular case of Thermal NDT. Typical task i.e. "yes/no and where" allows to classify the method as qualitative thermography. Simultaneously of vital value are: proper knowledge about evolution of radiant signals in the time domain and choosing of adequate procedures. This is typical for dynamic QIRT methods, which expand fast their application areas. Typical quantitative dynamic procedures for conditions partly like considered, i.e. using solar radiation as a heating source, were presented for surveys of facades and fresco [3]. In 1996 Simarad patented his idea of "the use of the temperature gradient as a tool to predict IR signatures of buried objects" based on assumption that there is a linear relation between the temperature contrast of the buried mines and the temperature gradient into the soil [4]. Such a method may be convenient for some applications on the field but is too simple for prediction or studying phenomena of the buried mines signatures.

In 1995 we started a small program with two aims: a) to evaluate conditions in which SW and LW cameras are able to detect buried mines under different conditions, b) to collect data useful for preparing better prediction procedures. Chosen results were presented previously $[5,6]$. Unfortunately, in our Polish conditions we noted a high false alarms rate caused by different "noises of the scenery" and any clear correlation between conditions of detection of buried mines was not found from these qualitative tests. As a result, the program was recently expanded, for studying of space and time dependent scenery's radiant features with the aim to elaborate more efficient procedures in using of IRT. 


\section{Experimental setup}

Fig.1,1a presents one of our measuring stand-ups used periodically since September 1995. Four antitank live mines (with damaged fuses...) had been buried in the sand at the depth shown. Additional elements of this stand-up typically consisted of: two passive radiators of blackbody and white-body types placed in the centre of the field, meter of the irradiance from the sky and contact sensors of the sand and mines temperature as well as multimeter of the wind speed, temperature, humidity, pressure of the air and "hot markers" in the corners of the field. The investigations were carried out using the AGEMA $900 \mathrm{SW}$ and LW cameras. All data were digitally recorded in various time sequences, adequate to the needs. Assistance PC software was elaborated and the base of experimental data was periodically completed.

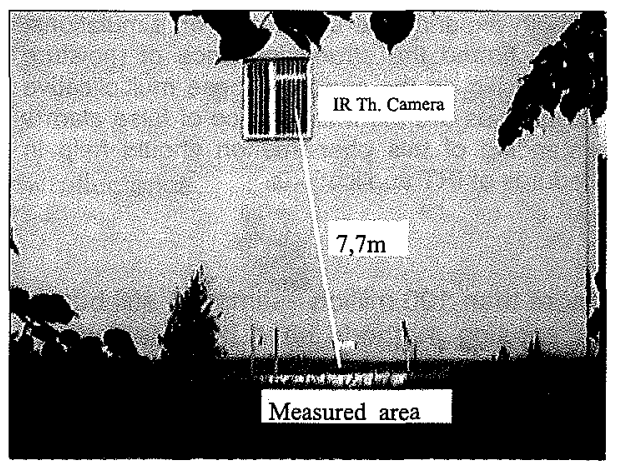

Fig.1. The measuring setup

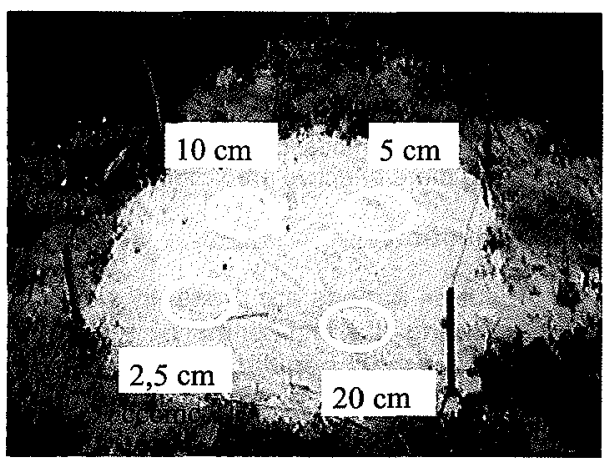

Fig.1a. The measuring area with mines buried at different depths

\section{Descriptive models}

Before describing the procedures that we used, it is very important to point the two mechanisms responsible for radiant signatures of the buried objects: "the surface effect" and "the volume effect". The first one is caused by burying operation which disturbs both the soil surface and the layer over the object. This effect disappears after a couple of days or weeks depending to the local features of soil. "The surface effects" can be characterised very similarly to structural noises caused by subsurface irregularities outside the buried mine. "Volume effect" is related to the differences between the overall thermal properties of the underground object, together with the perturbed soil layer covering it, and the thermal properties of its surroundings. This effect can be treated similarly to the defects in the TNDT.

The key and specific element of IRT application for detection of the underground, passive type objects like mines, is using a criterion of the different response of the soil surface for the solar heating activity depending on the disturbances of thermal properties of the subsurface structure caused by the buried mine. Unfortunately, both the surface temperature and its radiant features, are strongly related to the atmosphere-soil interface. In result, modelling supporting mentioned tasks has to consist of two models: "radiant" and "thermal".

\subsection{Model of incoming IR signals}

The model of incoming IR signals teaches conditions for a moment of potential IRT "snapshot". The radiant signal from the element of the object plane to a detector plane, for the case of partly cloudy, can be expressed by the known equation: 


$$
S=\iint_{\omega}\left\{\left[\left(1-\varepsilon_{g r}\right) S_{s k y^{\prime}-g r}+\varepsilon_{g r} L\left(T_{g r}\right)\right] \tau_{g r-c a m}+S_{g r-c a m}+\Gamma_{x o l}\right\} S_{\lambda, c u m} d \lambda d \omega
$$

where:

$$
S_{s k y-g r}=\int_{2 \Pi}\left[p\left(S_{\text {cloud }-g r}\right)+(1-p)\left(S_{\text {clearsky }}+\Gamma_{s u l-g r}\right)\right] d \Omega
$$

$\Gamma_{\text {sol }}, \Gamma_{\text {sol-gr }}$ - solar irradiation of the camera's optical aperture and ground respectively,

$\mathrm{T}_{\mathrm{gr}}$ - absolute temperature of the considered element of the surface,

$S^{*}$ sky-gr-ground irradiation from the cloudy sky reflected in direction of the camera,

$S_{\text {cloud-gr }}$-ground irradiation from the cloud,

$S_{s k y-g r}$-ground irradiation from the cloudy sky,

$S_{\text {gr-cam }}$ - IR camera irradiation from atmospheric path between object and camera

$S_{\lambda, \text { cam }}$ - relative spectral characteristic of the IR camera,

$\varepsilon_{\mathrm{gr}}$ - coefficient of emission of the surface's elements,

$\tau_{\mathrm{gr}-\mathrm{cam}}$ - coefficient of absorption in atmospheric path between surface and camera,

$p$ - ratio of cloudy/clear sky.

By nature of things, most of elements in equations (1), (2) proved time dependent features. It is clear that some of them are periodical, other accidental; some transferred to IR camera directly, other came out with various delays. To solve practical problems of detecting buried mine, the aborved quation seems to be much more important for prediction of surveys than for interpretations of thermograms. Nowadays, there are many similar models and software useful to estimate the considered problems, which are based on versions elaborated yet in 80 's because of their vital role in various military applications of IR imaging. We use PC ModWin and self-made software for PC.

\subsection{Thermal signatures of the mine and its surroundings}

Any more detailed analysis of thermal signatures of the mine and its surroundings has to be based on some assumptions and simplifications. This teaches to soil's cover and thermal properties of soil's underground structure including features of the mines as well as number of data about the history and the present state of the environmental influences.

From the viewpoint of the soil and mine ability to conduct and accumulate heat the principal thermal properties are: the thermal conductivity " $\lambda$ ", the heat capacity " $c$ " and for transient processes the thermal diffusivity " $\alpha$. From the viewpoint of thermal patterns on the soil surface, the principal elements to be considered are heating / cooling conditions and spatial features of considered elements in the soil. In this phase of research we use two separate models, presented below.

\subsubsection{Model to determine thermal properties of the soil}

A complete model describing the state of a coupled heat load system associated with a buried mine can be derived by considering the system as being spatially distributed. The soil is a multi-component system; therefore its thermal properties depend on many factors: mineralogical composition and organic matter content, structure, granulometric and aggregate size distribution and moisture. Soil moisture, for its given structure, depends on the relation between solid, liquid and gaseous phases and exerts the strongest effect on soil thermal conductivity - which acts the main part of the heat transfer modes in soil.

We use numerical model and software elaborated in Lublin Institute of Agrophysics presented in $[7,8]$. In this model the volumetric unit of soil, consisting of particles water and air, is treated as a system made of elementary geometric spheres that form overlapping layers (Fig.2). It is assumed that connections between layers of the spheres and the layer between neighbouring spheres are represented by serial and parallel connections of thermal resistors, respectively. The average value of thermal conductivity of soil is estimated from the resulting thermal resistance and average resistance of the corresponding flat layer. 

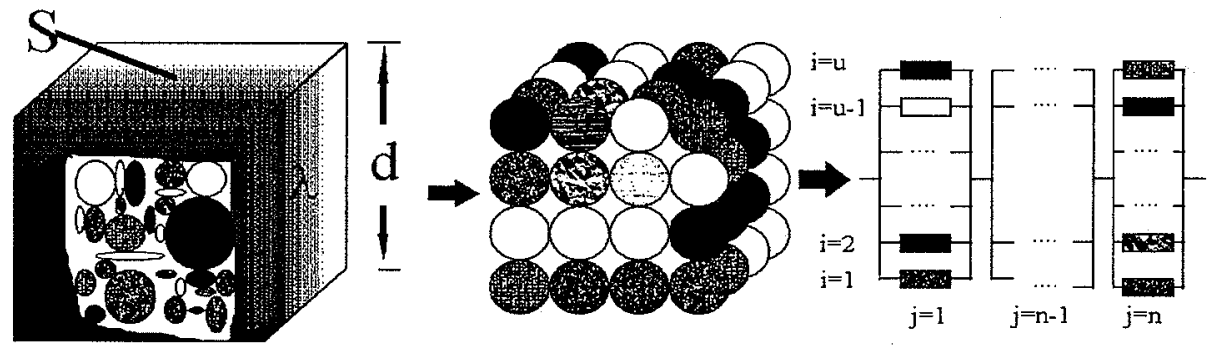

Fig. 2. Idea of modelling of thermal conductivity of soil follows

The main formula for calculating the average thermal conductivity coefficient of soil is as

$$
\lambda=\frac{4 \pi}{m\left(\theta_{\gamma}, \Phi, \mathrm{T}, r, u\right) u}
$$

where: $m(. .$.$) - expected value, related to water content in a unit volume of soil- \theta_{v}$, soil porosity - $\Phi$, temperature - $T$, sphere radius - $r$, and number of parallel connections of thermal resistors - $u$. These resistors represent water, mineral and organic ingredients in soil.

Based on the presented statistical-physical model of thermal conductivity and heat capacity, calculaed by means of de Vries formula, thermal properties of various types of soil, including sand as a simplest case, can be estimated in function of the moisture and level of the soil density. The error in assessing needed data did not exceed $+-10 \%$ of the values measured for various sand, clay, silt loam and peat types of soil.

The above mentioned data together with geometrical and thermal features of mines were used to estimate radiant properties of sand with and without a buried mine. The heat diffusion phenomena occurring over underground "defects" were analysed as below.

\subsubsection{Model to determine thermal patterns on the surface of the soil}

At the moment, we use "Thermo.Heat" software (developed at Tomsk Polytechnic University), which relates to transient thermal tests. Calculations were made basing on 2D heat equation for the sinus type heating of the three-layer model of cylindrical geometry and for cooling by convection. Similar to methodology presented in [9], to treat experimental results in time domain, we checked "TermidgePro" software (from Tomsk, too). In this paper it is only possible to mention that there softwares enabled us to estimate surface (or underground) thermal images for various combinations of simulated and real conditions with enough efficacy for this phase of our task.

\subsection{Processing of data}

Total noise in the present case was the sum of: noise from external sources (nonuniform heating/cooling conditions), noise caused by inhomogenity of investigated surface as well as noise from the detector and electronic noise. Integral software of AGEMA cameras has been used for averaging short sequences of thermograms, that decreased only the two last types of noise. Some other, commercial software to compress the dynamic range of raw images as well as to contrast enhancement has been tested with only partial successes.

\section{Results and discussion}

Figures 3-5 present the results of estimations influence of moisture and density levels " $\rho$ " of the upper, $2.5 \mathrm{~cm}$ depth, layer for chosen case of heating sand with the mines buried at 
shown depth ( the bold line for $\rho=1.8$, the dashed line for $\rho=1.2$ and the thin line for $\rho=1.0$ ) for "running contrast" $A h=\left(T_{\text {"defect" }=\text { mine }}-T_{\text {"nd" }}\right.$ =sand $) / T_{\text {"nd"=sand }}$ at the surface of sand.

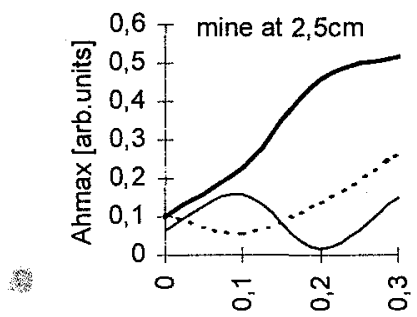

Water content $\left[\mathrm{m}^{3} / \mathrm{m}^{3}\right]$

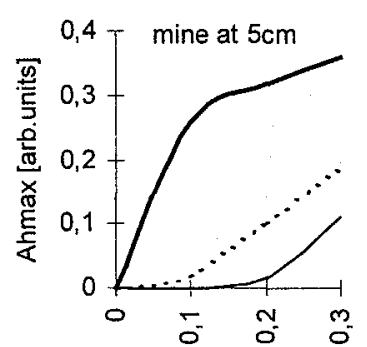

Water content $\left[\mathrm{m}^{3} / \mathrm{m}^{3}\right]$

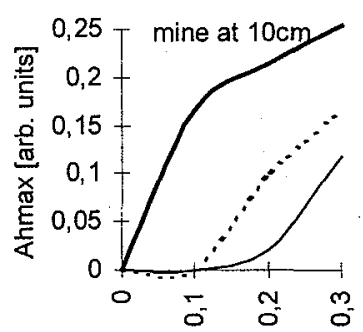

Water content $\left[\mathrm{m}^{3} / \mathrm{m}^{3}\right]$

Fig. 3.

Fig.5.

Figures quantitatively confirm expected strong influence of changes of the density and moisture in dry sand for transient thermal processes. More similar analyses for different simulated cases were done. For example, simulation of wetting thin upper layer of the dry soil or local changes of the density of these layers seem to explain "natural thermal patterns" observed even on flat surfaces which are responsible many of "false alarms" whem using IR thermal imaging for detection of buried mines...

Figures 6-8 present examples of experimental results of "volume effects" with use of typical in TNDT definition of "normalised contrast" i.e. CRn $=100$ (M2.5 - surf.)/(M2.5+surf.)

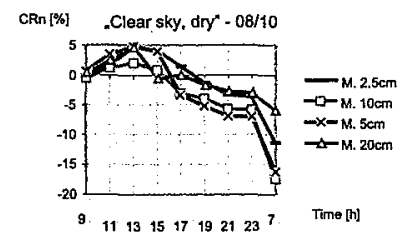

Fig. 6.

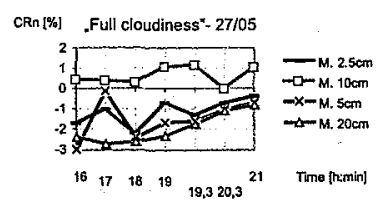

Fig. 7.

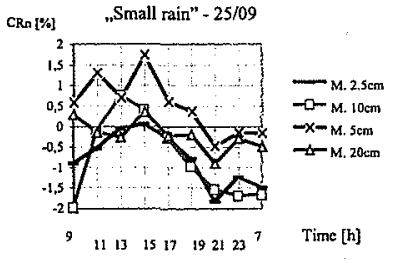

Fig. 8.

Dependence of volume effects on different state of weather, etc. is clearly seen. Obtained levels of "normal contrasts" usually were high enough to consider the application of new methods based on time-domain analyses. Unfortunately, it must be pointed that because of very high level of "false alarms" these results were obtained only because of our knowledge about places of buried mines... Similarly, we were unable to found any clear correlation between meteorological history and conditions for detection of respective mines. Based on large number of experimental data, we tested many ideas and TNDT methods and stated that, without much deeper understanding of relationships between object of investigations and both thermal and radiant conditions, elaboration of more effective predicting and searching procedures would be impossible. This was the main reason of extending our program for modelling thermal and radiant signatures of the buried objects for various IR thermal detection tasks. The initial results encouraged us to continue this direction.

\section{Conclusions}

Developed modelling and methods of calculations, although presently time consuming proved to be useful for studying complicated nature of radiant contrast features of buried 
mines. Results of simulations and measurements, although hard to compare at the moment, confirmed expectation that high level of "radiant noises" is caused mainly by differences in the moisture and sand density levels. During daytime surface thermal patterns, mainly created by the upper - even very thin - layer, strongly mask volume effects of the buried mines. Differences in moisture content in sand are particularly strong at lower global moisture contents and low density levels.

Choosing an informative criterion and method of thermograms processing based on the dynamic QIRT TNDT rules appeared to be a hard task. Although processing of sequences of thermograms instead of single one, increased detection efficiency a little, all the procedure is rather an art than a craft yet. Authors hope that future works on mentioned program will help to change this state.

\section{Acknowledgements}

The authors gratefully acknowledge Dr Usowicz and MSc. Szabra for valuable collaboration and State Committee for the Research Sciences for supporting this work with a grant.

\section{REFERENCES}

[1] TEBO (A.) - Abandoned land mines - Warfare's tragic legacy, Optoelectronic Reports, August 1996, p.3,15.

[2] SMITH (D. L.) - Detection Technologies for Mines and Minelike Targets, Proc. of SPIE Vol. 2496/ 1995, p.404-408.

[3] GRINZATO (E.), BISON (P.), MARINETTI (S.), VAVILOV (V.) - Nondestructive Evaluation of Delamination in Fresco Plaster Using Transient IRT", Res. NDT Evaluation (1994), 5:257-274, Springer Verlag, New York Inc.

[4] SIMARD (J.-R.) - Improved Landmine Detection Capability (ILDC): Systematic approach to the detection of buried mines using passive IR imaging. Proc.SPIE, Vol.2765,1996, p.489-.

[5] PRĘGOWSKI (P.), SWIDERSKI (W.) - Detection of minefields using IR sensing and timedomain treatment method, Proc. SPIE, Vol. 3079, 1997, p.791-800.

[6] PRĘGOWSKI (P.), SWIDERSKI (W.) - Using of comparison method in IR Thermal detection of buried mines, Proc. SPIE, Vol. 3392, 1998, p.791.

[7] USOWICZ (B.) Statistical - Physical Model of Thermal Conductivity in Soil, Polish Journal of Soil Science, 1992, p.25-34.

[8] WALCZAK (R.), USOWICZ (B.) - Soil temperature prediction by numerical model, Polish Journal of Soil Science, 1995, p.86-94.

[9] VAVILOV (V.), MARINETTI (S.), GRINZATO (E.), BISON (P.G.), ANTOSHKIN (I.), KAUPPINEN (T.) -Transient thermographic detection of buried defects: attempting to develop the prototype basic inspection procedure, Proc. of QIRT'96, Stuttgart, Edizioni ETS, Pisa, 1997, p.239-244. 